\title{
Construção ficcional e fendas documentais em Ventos de Agosto
}

\section{Eduardo Paschoal de Sousa}

Mestrando do Programa de PósGraduação em Meios e Processos Audiovisuais da Escola de Comunicações e Artes (ECA-USP) na Linha de Pesquisa Cultura Audiovisual e Comunicação.

E-mail: eduardopaschoals@gmail.com
Resumo: Este artigo reflete sobre os vários planos narrativos no longa Ventos de Agosto (Gabriel Mascaro, 2014) e como a diegése ficcional é interrompida por imagens sensivelmente documentais, representando uma ruptura em sua cadência narrativa. Para isso, analisa algumas operações necessárias à ficção clássica em um discurso cinematográfico - como a figurativização, o apagamento do suporte e a criação diegética - e de que forma elas não se concretizam em muitos momentos do filme, em que há uma aproximação às características que tendem ao documental. Por fim, busca compreender a obra como um discurso híbrido, resultado de um entremeio narrativo.

Palavras-chave: Ficção; Documentário; Diegése; Narrativa; Discurso cinematográfico.

Fictional construction and documentary fissures in Ventos de Agosto (August Winds)

Abstract: This study reflects on the multiple narrative plans in the movie Ventos de Agosto (August Winds, Gabriel Mascaro, 2014) and how the fictional diegesis is interrupted by significantly documentary images, representing a disruption in its narrative cadence. With this purpose, we analyze some operations required to the classic fiction in a cinematographic discourse - such as figurativization, erase of the support and diegetic creation - and how they are not materialized in many moments of the film, in which there is a great approach to the characteristics that tend to documentary. Finally, we aim to understand the movie as a hybrid discourse, the result of an intermediate narrative space.

Keywords: Fiction; Documentary; Diegesis; Narrative; Cinematographic discourse. 
O cenário bucólico de um barco navegando calmamente por um rio e, na sequência, pelo mar, é interrompido pelo punk rock na pista sonora e pela imagem de uma lata de Coca-Cola usada como bronzeador. Ventos de Agosto (Gabriel Mascaro, 2014) é repleto dessas rupturas em sua cadência narrativa - ora mais bruscas e acentuadas, ora mais sutis. O longa conta a história de Shirley, que teve de sair de onde morava, aparentemente uma cidade grande, e voltar a viver em uma pequena vila no litoral para cuidar da avó doente.

Mesmo com esse deslocamento abrupto na trajetória da personagem, ela leva consigo seu gosto musical, o sonho de ser tatuadora e a vontade latente de sair dali e voltar para o seu lugar. Trabalha em uma fazenda de cocos dirigindo um trator e tem uma relação afetiva com Jeison, morador do mesmo povoado que ela. Ele também trabalha com o coco e com pesca subaquática, o que fica evidenciado logo nas primeiras cenas do filme, quando joga para cima do pequeno barco onde Shirley toma sol um polvo que acabara de pescar.

O que faz de Ventos de Agosto um filme de diversas fendas e rupturas são seus planos narrativos, que se acumulam ao longo da obra. Primeiro, há a relação da protagonista com a avó e o namorado, uma maneira um pouco fria e por vezes indiferente de se relacionar; em um segundo plano, há a comunidade para onde teve de voltar, um pequeno povoado com suas especificidades, como o vendedor de quadros fotográficos que passa de porta em porta vendendo suas obras. No meio da trama, surge a figura de um pesquisador - interpretado pelo próprio diretor do filme - que busca registrar os ventos do local com um microfone, um gravador e um pequeno aparelho que se move de acordo com as correntes eólicas: um terceiro plano narrativo, que é de certa maneira desconectado dos demais. Seu contato é mais incisivo na vila de moradores que na história principal do filme, apesar de manter um diálogo breve com Jeison sobre o pulmão das pedras. Há, ainda, o caso de um cadáver que aparece misteriosamente pelo mar e dá o tom tragicômico ao filme, quase em seu final, se tornando uma quarta etapa da história.

Do mesmo modo que Shirley algumas vezes demonstra ser uma estranha naquele lugar, também a diegése narrativa ficcional parece não estar em operação todo o tempo. Há um aparente incômodo de quase todos os atores do filme frente à câmera - sentido principalmente com os habitantes do vilarejo -, o que lança uma dúvida documental no registro da imagem em Ventos. Há uma aparente fenda na narrativa ficcional conduzida especialmente pelo incômodo da imagem e da câmera frente à vida cotidiana daquele lugar. É a partir desse desconforto que buscamos fazer essa reflexão sobre a obra: um desconforto que parte da narrativa ficcional, mas que atinge o leitor do filme em sua percepção da imagem. Uma fenda que irrompe da ficção e expande seus territórios, gerando um discurso fílmico híbrido, que não se encontra na narrativa ficcional clássica, mas cuja diegése impede que seja ancorado no documentário.

\section{O caminho ficcional}

Antes de abordar as características do filme, seja ele no campo da ficção ou do documentário, é necessário assumirmos o cinema como discurso e também entendê-lo como construção: muito além da fixação do mundo em seu fotograma, uma criação da realidade intrínseca à tela. Xavier (2005) contribui para compreendermos o cinema como um discurso "a rigor, sempre ficcional, em qualquer de suas modalidades; sempre um fato de linguagem, um discurso produzido e controlado, de diferentes formas, por uma fonte produtora" (XAVIER, 2005: 14). 
Segundo o autor, esse discurso pode ser mais opaco ou mais transparente, deslizando por esse espectro mas nunca totalmente polarizado para um ou outro extremo. Aquele que se encaixaria em um discurso mais opaco é construído pela tentativa de apagar o aparato cinematográfico, busca tornar a narrativa mais naturalizada e detentora da verdade da história, investindo fortemente na diegése fílmica, como construção de um mundo próprio ao filme. Já os que tendem à transparência evidenciariam todo aparato próprio do cinema, e tentariam agir como uma janela para o mundo. Por mais que isso não seja possível, há ao menos uma tentativa de construção dessa pretensa transparência no filme.

Ainda que por vezes a imagem cinematográfica construa um discurso próprio, uma acepção individual do mundo, um enquadramento específico de uma realidade, não se trata de dizer que o cinema é uma arte falsa, ou como afirma Aumont (2002: 111), que o cinema seja ilusionista, nem que "gere fenômenos de crença necessariamente mais fortes do que outros. Simplesmente, o espectador de filme está mais investido de forma psicológica na imagem". A criação de um mundo particular ao filme dá ao cinema a potência de identificação do sujeito que o assiste, de perpetuação do olhar à tela, de assimilação mais intensa de um mundo próprio.

Apesar de partir do pressuposto de que cinema é discurso, há diferentes formas de acepção discursiva, principalmente no que diz respeito ao cinema ficcional e ao documentário. Nichols (2005: 55) aponta para essas diferenças fundamentais desde a concepção do filme, mas incisivamente na etapa da montagem. Para ele, o filme que tende mais ao documental está menos preocupado com a montagem em continuidade, ou seja, aquela que opera para tornar invisíveis os cortes e rupturas entre os planos de um filme. O que na fiç̧ão é conseguido com a continuidade das tomadas, no documentário é elaborado pela própria história. Dessa forma, as situações se ligariam no tempo e no espaço não pela montagem, mas por suas reais ligações, pela suas correspondências histórico-temporais.

Podemos refletir sobre essa estrutura em Ventos de Agosto, cuja preocupação com a continuidade é relativa. Por mais que em um plano narrativo inicial aquele que segue a história de Shirley e sua nova trajetória pelo povoado em que mora sua avó - haja uma continuidade e uma certa conformidade narrativa, que se preocupa em seguir uma lógica ficcional, há interrupções nessa condução, como a chegada de um pesquisador aos 30 minutos de filme, que rompe com a lógica da continuidade da obra e cria uma outra camada interpretativa.

Essa alteração é conduzida em grande parte por uma decisão da montagem, já que se essa intrusão do personagem fosse em qualquer outra parte do filme não alteraria a construção narrativa principal. Tanto que ela não tem relação direta com os demais planos do filme, a não ser pelo contato entre o pesquisador e Jeison, que ocorre desconectado de outros fatos narrativos: não há um diálogo ou uma tomada que inclua Jeison, Shirley e o pesquisador; os protagonistas não comentam sobre esse sujeito que surge no povoado para registrar os ventos; não há uma menção em nenhum outro momento a respeito dele ou de sua atividade profissional ali.

Se essa interrupção narrativa é contornada pela interação com Jeison, talvez seja para evitar o que Odin (2000: 36) classifica como defasagem, um rompimento narrativo brusco. Ele é causado, segundo o autor, quando as cenas exibidas no filme não estão em consonância com a narrativa, ou quando há uma conjunção de planos de forma aleatória, sem que eles estejam a serviço da cadência daquela história. Essa hierarquia de planos na ordenação narrativa é muito cara à ficção. Sem ela, não há um efeito de convencimento e de 
concatenação da lógica ficcional, o que se caracterizaria por um rompimento da própria estratégia da ficção de forma ampla e que agiria no conjunto do filme, não apenas na narrativa.

Outra estratégia é usar uma referência temporal na ação do pesquisador, marcada pelas mudanças do clima, a chuva, o céu aberto, o sol e o vendaval, mas nunca pela ação das outras personagens. É como se houvesse um plano narrativo paralelo que se desenrola enquanto a vida de Shirley passa. Não há conexão, nem uma continuidade narrativa. Acreditamos que a inserção do pesquisador tende ao documental, porque se o espectador do filme não conhecesse Mascaro, ou não soubesse que é o próprio diretor que interpreta aquele personagem, poderia facilmente confiar que ocorreu aquela captação dos ventos, pois não há nenhuma ligação dessa sequência com o restante da narrativa, nem há uma lógica ficcional interna ao filme nesse desenrolar.

E o longa investe nesse estranhamento pela reação dos próprios personagens, moradores da aldeia. Em um trecho próximo ao final dessa sequência de dez minutos, o pesquisador se senta com algumas meninas na calçada de uma das casas e interage com elas, permitindo que elas brinquem com o microfone e ouçam o que está sendo gravado. Não parece haver ali um roteiro préestabelecido, nem ao menos sentimos que aquelas garotas estão interpretando. Há um rastro documental nessa participação que nos leva a perceber que elas estão desempenhando seus próprios papeis, surpresas por aquela presença, que para elas se justificaria pela gravação de um filme ficcional, mas para o espectador, investido da diegése da narrativa, é a relação de um pesquisador dos ventos com a comunidade local, e por isso a estranheza da população.

Nichols (2005: 58) afirma que essa tentativa de persuasão e de convencimento na representação, aqui simbolizada pela evidência do aparato cinematográfico e da garantia diegética de que o som parte do gravador em cena, com crianças que não estão completamente cientes de uma interpretação em um filme ficcional, mas que reagem espontaneamente diante da câmera, é mais evidente em filmes documentários que ficcionais. Segundo o autor, é por essa correspondência ao mundo que se preocupa o documentário, não pelo fascínio da fabricação do discurso fílmico, uma lógica mais informativa que ficcional.

Essa seria uma forma de transparência, de evidenciação de um mundo histórico retratado e enquadrado no discurso fílmico. Enquanto o cinema ficcional clássico envida grandes esforços para apagar o aparato fílmico (que inclui não só a câmera, mas também todas as outras instâncias da fabricação de sentidos, com a montagem inclusive), o cinema documental aparentemente busca evidenciá-lo, como forma de construir a verossimilhança e a referencialidade, fazer com que a imagem em tela esteja mais próxima ao mundo histórico visto fora daquele quadro.

No entanto, ainda que haja alguns traços documentais nessa e em outras cenas de Ventos de Agosto, é mais comum que o espectador volte ao entendimento do filme como uma obra de ficção, da forma como ele está indexado. Para Odin (2000: 11), a ficcionalização, ou o processo de compreensão da obra fílmica como uma ficção, tem um status privilegiado em nosso espaço sociocultural. Para ele, o desejo da ficção se manifesta no interior de cada um de nós e é inerente a nossa estruturação psíquica.

O autor acredita não ser exagerado afirmar que a ficcionalização esteve e ainda está no cerne da maior parte das nossas experiências de leitor ou espectador. Para ele, a utilização desse modo não necessita de um contrato institucional anterior, não é necessário dizer ao espectador que o que ele vê é uma ficção, já 
que essa percepção faz parte de uma ordenação psíquica que nos leva a compreender a maior parte das obras literárias e cinematográficas como uma fiç̧ão, sem um grande esforço para as aceitar.

Odin estrutura em sua obra De la fiction (2000) a maneira como o modo ficcionalizante deve agir para conduzir à ficção, ou seja, um sistema de processos que se articulam e que correspondem a tarefas que devem ser cumpridas para que a ficção seja completa e ative no imaginário do espectador essa forma de olhar para o filme. $O$ início desse processo se dá com a necessidade da diegése, ou a construção de um mundo inerente à obra.

Além de Odin, Schaeffer (1999) também corrobora com a necessidade diegética na obra, o que ele chama de "imersão ficcional". Para ele, sem ela não há a criação de um mundo que permita a assimilação da história por parte do leitor. E mais do que a elaboração de uma realidade, esta deve ser crível, conter uma lógica interna que dê a aparência de verdade ao leitor, não de fingimento. Em um discurso diegético, há sentido naquela criação, há um pacto que a obra faz com o seu leitor convidando-o a compartilhar o mesmo mundo, a habitar o mesmo espaço da obra durante aquele período de imersão.

A construção desse universo onde o leitor é convidado a permanecer é possível graças a três operações, segundo Odin (2000: 23). A primeira é a figurativização. Ela funciona como um mecanismo de analogia dos elementos do mundo aos elementos da tela. É por meio dela que se tem a impressão de realidade, construída a partir de um espaço de signos simbólicos que estão no lugar de algo no discurso cinematográfico. A analogia figurativa muitas vezes não é constatada, mas pressuposta.

Não é necessário que o leitor identifique imediatamente as alegorias e que faça analogia a algum mundo (histórico ou fantasioso), mas que considere que eles são representantes dos elementos de um mundo, que haja uma lógica que permita ter ou não a possibilidade de verificar a semelhança com esses elementos. Um objeto não precisa ter o formato de uma faca ou de um machado para que se identifique que ele é cortante e que representa um risco na história, desde que ele seja figurativizado como um objeto cortante, que o leitor o veja realizando a ação de cortar, ou ainda que compreenda, naquelas circunstâncias, que há esse risco.

Odin (idem) observa que apenas a figurativização não é suficiente para que a obra seja diegética, mas sim ver um mundo ao invés e no lugar dessas imagens na tela. Além de figurativizar, é necessário dar a impressão de realidade para esse mundo elaborado na história.

Ventos de Agosto utiliza várias estratégias de figurativização para construir esse pacto ficcional. A mais importante delas, talvez, é a preocupação com a correspondência documental, uma decisão que é tomada mesmo antes da finalização da própria obra, como filmar em uma vila de pescadores que já existia, que não foi criada para o filme, mas que pode ter sua existência comprovada antes e depois das gravações, uma forma de reforçar a correspondência do filme com o mundo histórico, portanto usando ferramentas típicas da estética documental.

Também há a gravação com atores não profissionais, como Geová Manoel dos Santos, que interpreta Jeison, um dos protagonistas. Essa estratégia, utilizada diversas vezes ao longo da cinematografia brasileira e mundial, tem o objetivo de tornar o discurso do filme mais verdadeiro, investi-lo de uma referencialidade 
mais próxima: o ator representa alguém muito próximo de sua realidade, ainda que tenha de seguir um roteiro que dá o tom ao filme.

Podemos observar essa incidência da busca pela correspondência à realidade em várias cenas do longa, como na dos quebradores de coco. $O$ filme, que se passa em um vilarejo próximo a um coqueiral, exibe por diversas vezes imagens dos trabalhadores da fazenda na atividade de colheita. Logo nas primeiras cenas, há um plano aberto que mostra um homem, posicionado na extremidade direita do quadro, subindo na árvore usando apenas as pernas para apanhar o coco, algo que notadamente exige um conhecimento aprofundado daquela atividade e é provável que tenha sido feito por alguém dali.

O mesmo ocorre em outro trecho, em que os trabalhadores quebram o coco com um objeto pontiagudo que os ajuda a descascá-lo. Essa atividade é realizada muito rapidamente, em um movimento preciso e repetitivo, mas aparentemente arriscado. Há, na própria imagem, uma correspondência documental que irrompe do quadro, uma documentarização da cena, como postula Odin (2012).

O autor compreende que há uma intepretação possível, por uma escolha apenas do espectador, que o leva a acionar uma leitura fictivizante (que tenderia ao ficcional) ou documentarizante (com apelo ao documental). Essa leitura independe do respaldo do realizador, da intencionalidade da obra ou de qualquer outra construção prévia, mas reside unicamente no entendimento do discurso por parte do leitor - aqui leitor empregado no sentido que o autor o trata, como o espectador que lê o discurso cinematográfico. $O$ que o leva a discernir sobre o filme é algo que não foi necessariamente premeditado pela obra, já que a leitura é um "efeito do posicionamento do leitor face ao filme, o resultado de uma operação externa ao filme: uma operação estritamente pragmática" (ODIN, 2012: 16).

É como se imaginássemos que ao retornar naquela localidade, um vilarejo no litoral, nos depararíamos com aqueles mesmos trabalhadores realizando a atividade de descascar o coco com a destreza e a rapidez que pudemos acompanhar nas imagens do filme. Ainda que não houvesse uma separação dos personagens de maneira individual, como é recorrente no documentário, a cena coletiva tem uma correspondência documental, como se o filme buscasse montar uma paisagem da atividade dos quebradores de coco.

Retomando à construção ficcional, Odin (2000: 23) aponta para a segunda operação responsável pelo efeito de mundo na obra: o apagamento do suporte. A aparição da câmera em tela, a quebra da quarta parede que separa público da obra ou a demonstração de que se trata de uma filmagem rompe com a diegése ficcional do filme. Mobilizar essa quebra às vezes é uma intenção clara da obra, com objetivos variados - a proximidade com o espectador, a demonstração do filme como construção, entre outros -, mas ela sempre leva a uma interferência no desempenho diegético.

É o que ocorre quando há a incidência de um personagem desconectado com a trama ficcional, o pesquisador dos ventos, e a consequente evidência do suporte utilizado para a gravação - de sua pesquisa, mas também dos sons do filme. Essa intrusão tenta ser justificada no roteiro como uma visita de alguém externo àquela comunidade, como já colocamos anteriormente, mas acaba por romper temporariamente a cadência narrativa e ficcional do filme. A tentativa de trazer a realidade ao filme pode ser percebida, por exemplo, em um trecho em que o pesquisador encontra uma mulher na porta de sua casa. Há uma música romântica de fundo, que parece ser extradiegética. Ele questiona se ela saberia dizer onde é melhor, na região, para capturar o barulho dos ventos. Ela se mostra 
confusa com a pergunta, muito deslocada do seu cotidiano, e diz não saber responder. Ele, então, pergunta se pode gravar um pouco o som em frente à casa dela, no que ela concorda e se afasta da porta, até sair completamente do quadro. O som se torna diegético na medida em que o microfone do pesquisador se aproxima da porta da casa daquela personagem e busca demonstrar que aquela música romântica, que ouvíamos ao fundo, vinha mesmo de um aparelho dentro daquela casa. A cena continua com o enquadramento estático, até que a música termina e há o corte.

A terceira operação de que trata Odin para a elaboração diegética da ficção é construir um espaço habitável ao espectador, ao menos que faça sentido ao mundo criado pela obra. Isso quer dizer que ele deve se sentir confortável com os elementos descritivos que foram mobilizados nessa elaboração, deve analisar e identificar com facilidade as correspondências dessas ferramentas e não ficar com dúvida de que esse é um mundo possível de se habitar.

Podemos refletir se essa tentativa, em Ventos de Agosto, não funcionaria novamente na própria escolha de uma locação com caráter documental. Ao eleger como cenário do filme um vilarejo um pouco desconectado e distante do universo urbano para uma história com traços um tanto fantasiosos - como o fato de surgir um cadáver desconhecido vindo do mar e que fica por vários dias convivendo na história e na vida de Jeison -, o filme busca um conforto para o espectador, uma forma de entregar um mundo possivelmente habitável, crível, ainda que articule uma narrativa parcialmente fantasiosa.

O que queremos exemplificar aqui é a necessidade de um mundo lógico e habitável, que não gere nenhum desconforto ao leitor quanto a sua existência no momento em que ele assiste àquela obra. Mais que uma correspondência com os elementos do mundo histórico, tem de haver uma aderência à lógica interna daquela obra e o uso do cenário documental cumpre esse papel no longa.

\section{O olhar para a câmera e o ponto de vista}

Aos seis minutos de filme, Shirley dirige o trator em direção à colheita do coco. Na carroceria, a câmera capta seis pessoas em pé que são transportadas pela protagonista e permanece fixa enquanto os olhares miram o horizonte. Inevitavelmente, e por repetidas vezes, eles se cruzam com a câmera, olham para o aparato e, consequentemente, para os olhos do espectador. Na estética clássica da ficção, esse movimento de olhares representa a quebra da barreira que separa o ator e o espectador, o quadro do cinema e o enquadramento da realidade.

Salvo raros momentos, dificilmente $\mathrm{o}$ ator olha fixamente para a câmera. Nesse caso, o movimento é compreensível se refletirmos que aqueles não eram atores profissionais e buscavam agir como agem em seu cotidiano, de forma natural apesar de a naturalidade da ficção demandar o cuidado para que o olhar nunca se cruze com a câmera. Esse reflexo de casualidade no olhar para a câmera reflete também uma intenção de realidade, uma forma de explicitar um rastro documental naquela imagem, que deixasse claro que a falta de se evitar a câmera era uma forma de dizer que aqueles atores interpretavam menos, ou traziam menos subterfúgios em suas interpretações.

Essa dúvida ficcional, fruto da relação dos personagens com a câmera, também surge em outra cena, aos vinte e cinco minutos do longa, em que Shirley e Jeison pegam uma carona com um ônibus escolar, no meio da estrada. Assim que entram no veículo, o quadro permanece estático no começo do ônibus, enquanto os protagonistas se acomodam em pé, ao fundo. O olhar das crianças para o aparato é constante, às vezes surpreso, às vezes condescendente. Elas olham 
${ }^{1}$ Dos originais: "Il n'y a donc pas d'histoire sans diégèse" e "Il n'y aurait donc de diégèse qu'à l'interieur d'une construction narrative" (ODIN, 2000:22). Tradução nossa. curiosas como se também estranhassem a presença do espectador ali, fazendo com que a presença do aparato cinematográfico fique evidente, sem que se explicite que há uma câmera empregada e que há uma filmagem.

A diegése é tão importante a uma obra ficcional que Odin é categórico em afirmar que "não existe, então, história sem diegése" e que "não haverá, então, diegése a não ser no interior de uma construção narrativa" ${ }^{11}$ (Odin, 2000: 22). É por meio dela que são fixadas as modalidades de manifestação dessa história, já que ela fornece os elementos descritivos por meio dos quais a história pode se manifestar, como relações pessoais, familiares, sociais, econômicas, religiosas, entre outras.

Ricœur (1994: 81) fala sobre o prazer do reconhecimento desse mundo no espectador, o "o fruto do prazer que o espectador tira de uma composição que respeita o necessário e o verossímil" e que, para ele, são mecanismos construídos e exercidos pelo próprio espectador. Ou seja, o leitor fica satisfeito em se colocar no mundo do filme e esse processo é estimulado pela diegése, que só se completa em sua própria percepção.

Temos de considerar, quando tratamos do rompimento diegético da fiç̧ão no caso de Ventos de Agosto, que há uma diferença na própria elaboração diegética entre a ficção, o documentário e também em outras linguagens. A diegése da ficção é construída com a construção de um mundo próprio à obra. Por mais que ela seja uma ficção, ela deve ter por objetivo a elaboração de uma realidade, conforme coloca Schaeffer (1999: 147), e não um fingimento, uma mentira. Apesar de partir do mesmo princípio - tanto a mentira quanto a construção de realidade são ilusórias -, a finalidade da ficção é partilhar uma mesma realidade, enquanto a do fingimento é deturpar essa realidade comum, enganar o espectador. Na fiç̧ão, não há uma verdade a ser descoberta a respeito deste mundo, o próprio mundo construído já é a verdade da obra, a verdade da ficção.

Já a diegése do documentário, conforme esclarece Nichols (2005: 57), é calcada no próprio mundo histórico, partilha das mesmas intenções e direcionamentos do referencial de mundo cotidiano. Em um documentário, podemos ter a necessidade de explicar a cadência de fatos que desencadearam um acontecimento maior, mas não precisamos detalhar, necessariamente, que esses fatos ocorreram em um mundo histórico compartilhado com o espectador do filme. Ainda que possa ser um mundo culturalmente diferente, portanto haja elementos que difiram do que nossos olhares estejam acostumados, eles fazem parte de uma única construção do mundo, a que se pretende realidade.

O autor compreende essa diferença por uma maior proximidade no documentário de vínculos indexadores de som e imagem do mundo histórico. Para ele, ao assistir a um documentário, o espectador está particularmente atento à maneira pela qual esses traços audiovisuais testemunham a aparência do mundo que compartilhamos. Esse vínculo atestaria um envolvimento do filme em um mundo que não é de toda forma resultante apenas daquele discurso: "quando supomos que um som ou uma imagem têm uma relação indexadora com sua fonte, essa suposição tem mais influência num filme que consideramos documentário do que num filme que consideramos ficção". O uso de uma evidente referencialidade em Ventos de Agosto o aproxima desse procedimento diegético mais documental que ficcional, já que movimenta a correspondência a um mundo histórico, e não apenas à diegése criada para a tela.

Quando colocamos essa quebra diegética na ficção como uma irrupção do documental no filme, o fazemos por entender que a criação de um mundo ideal à narração é um traço fundamental para a ficção; e quando esse artifício é 
rompido, há uma mudança no status ficcional junto do leitor, abrindo uma lacuna de hibridismo na narrativa, que não passa a ser puramente ficcional, mas pode ser interpretada e interligada com outros territórios do cinema.

\section{A estranheza da ficção}

Seja pelo olhar para a câmera, sejam pelas interrupções narrativas que tendem ao documental, Ventos de Agosto é um filme que deixa evidente uma certa estranheza ao ficcional, que percorre todo o filme. No plano narrativo, é como se o incômodo sempre presente no deslocamento forçado de Shirley para aquele povoado seja análogo ao posicionamento dos demais personagens frente ao filme.

O hibridismo presente o tempo todo, evidenciado pela referencialidade da imagem documental que insiste em permanecer na diegése ficcional da narrativa, parece fazer parte desse deslocamento da personagem, como se o documental presente no cotidiano daquele vilarejo fosse interrompido pela abrupta presença de Shirley - e da ficção.

Nesse plano, a protagonista e a fiç̧ão insistem em se firmar como estranhos àquele contexto, um não-pertencimento bastante claro, que busca se evidenciar em pequenas reações - a tatuagem que Shirley faz em um animal, em uma cena bastante impactante, ou nos olhares inevitáveis dos atores não profissionais para uma câmera que está ali o tempo todo e que tenta se apagar para que a criação diegética seja mais efetiva.

Não nos cabe questionar se essa fenda documental foi uma escolha de realização da obra, mas sim considerar que ela se faz presente na leitura do filme, evidenciada por pequenos gestos ou por grandes quebras de cadência. Ventos de Agosto conduz o espectador por muitos planos narrativos, em uma sequência de rompimentos e rearranjos, mas deixa evidente que há, tanto em sua protagonista quanto na imagem do filme, uma grande potência de ruptura.

\section{Referências}

AUMONT, J. A imagem. Campinas: Papirus, 2002.

NICHOLS, B. Introdução ao documentário. Campinas: Papirus, 2005.

ODIN, R. De la fiction. Paris: De Boeck Université, 2000.

Filme documentário, leitura documentarizante. Significação Revista de Cultura Audiovisual. São Paulo, v. 39, 2012.

RICCEUR, P. Tempo e Narrativa (tomo I). Campinas: Papirus, 1994.

SCHAEFFER, J. Pourquoi la fiction?. Paris: Seuil, 1999.

\section{Filmografia}

VENTOS de Agosto. Direção: Gabriel Mascaro. Desvia. 2014, Brasil. 77 minutos, cor. 